\title{
MENINGKATKAN MOTIVASI BELAJAR SISWA DENGAN \\ MENGGUNAKAN MODEL KOOPERATIF TIPE STUDENT \\ TEAMS ACHIEVEMENT DIVISION (STAD) PADA MATA \\ PELAJARAN IPS DI KELAS V SDN 107402 SAENTIS
}

\author{
Herawaty Bukit \\ Surel: herawaty.bukit@gmail.com
}

\begin{abstract}
ABSTRAK
Penelitian ini bertujuan untuk meningkatkan motivasi belajar siswa pada pembelajaran IPS dengan menggunakan model pembelajaran Student Teams Achievement Division (STAD) di kelas V SD Negeri 107402 Saentis. Subjek penelitian ini adalah siswa kelas V SD Negeri 107402 Saentis yang berjumlah 33 orang. Data hasil observasi kegiatan guru pada Siklus I pertemuan 1 dengan rata-rata rendah $58,30 \%$, Siklus I pertemuan 2 dengan rata-rata tinggi $73,61 \%$, Siklus II pertemuan 1 dengan rata-rata sangat tinggi $84,72 \%$, Siklus II pertemuan 2 dengan rata-rata sangat tinggi 91,66\%. Dari data observasi siswa pada Siklus I Pertemuan 1 motivasi belajar siswa rendah dengan rata-rata 50\%, Siklus I Pertemuan 2 motivasi belajar siswa tinggi dengan rata-rata $62,5 \%$, Siklus II Pertemuan 1 motivasi belajar siswa tinggi dengan rata-rata 75,09\%, dan Siklus II Pertemuan 2 motivasi belajar siswa sangat tinggi dengan rata-rata $84,84 \%$. Dari hasil data yang diperoleh dapat dilihat terjadi peningkatan motivasi belajar siswa, sehingga disimpulkan bahwa dengan menggunakan model pembelajaran Student Teams Achievement Division (STAD) dapat meningkatkan motivasi belajar IPS siswa kelas V di Negeri 107402 Saentis.
\end{abstract}

Kata Kunci : Model Pembelajaran, Motivasi Belajar, STAD

\section{PENDAHULUAN}

IPS merupakan ilmu yang mencitrakan manusia ditengah-tengah masyarakat secara individu atau sebagai anggota masyarakat. Melalui mata pelajaran IPS di Sekolah Dasar diharapkan dapat memiliki pengetahuan dan wawasan tentang pelajaran IPS, memiliki kepekaan dan kesadaran terhadap masalah sosial di lingkungannya, serta memiliki keterampilan mengkaji dan memecahkan masalah-masalah sosial tersebut.melalui mata pelajaran IPS dapat terbina menjadi warga Negara yang baik dan bertanggung jawab.
Tujuan dari pembelajaran IPS adalah untuk mengembangkan potensi peserta didik agar peka terhadap masalah sosial yang terjadi di masyarakat, memiliki sikap mental positif terhadap perbaikan segala ketimpangan yang

Berdasarkan

tujuan

pembelajarn IPS, guru harus mampu membelajarkan peserta didik pada lingkungannya dalam mencari solusi atas berbagai masalah yang ada dilingkungan tersebut. Supaya siswa memperoleh pengalaman belajar yang bermakna yang dapat diterapkan dalam kehidupan sehari-hari.

Dosen Jurusan PPSD Prodi PGSD Unimed 
Namun kenyataan dilapangan sewaktu PPLT menunjukkan bahwa pembelajaran IPS kurang minati siswa dari rendahnya motivasi belajar siswa dikelas. Hal ini karena Rendahnya motivasi belajar siswa siswa pada pembelajaran IPS (Ilmu Pengetahuan Sosial) disebabkan karena kurang tepatnya model pembelaran yang digunakan pada saat proses belajar mengajar berlangsung didalam kelas. Model pembelajaran yang diterapkan oleh guru tidak bervariasi sehingga motivasi belajar siswa menjadi rendah.

Rendahnya motivasi belajar juga terjadi karena banyaknya siswa tidak memahami materi yang disampaikan oleh guru dalam belajar IPS karena cenderung menggunakan metode ceramah. Dalam hal ini proses belajar siswa dalam pembelajaran IPS hanya melalui menghafal dari apa yang didengar ataupun yang ditulis oleh gurunya, serta penerapan model pembelajaran Student Teams Achievement Division (STAD) belum pernah sebelumnya digunakan saat mengajar oleh guru terutama dalam mata pelajaran IPS (Ilmu Pengetahuan Sosial). Hal ini mengakibatkan kemauan atau keinginan siswa dalam pembelajaran IPS menjadi kurang. Dilihat dari banyaknya siswa jenuh dan bosan dalam mengikuti pembelajaran IPS dikelas.

Oleh karena itu, untuk mengatasi masalah diatas, guru diharapkan mampu memilih dan mengembangkan model pembelajaran yang sesuai dengan pembelajaran yang akan disampaikan. Salah satu model pembelajaran yang dapat diterapkan untuk meningkatkan motivasi belajar siswa ialah dengan menggunakan model pembelajaran kooperatif tipe STAD (Student Tiems Achevement Division).

Pembelajaran kooperatif tipe STAD merupakan salah satu tipe dari model pembelajaran kooperatif dengan menggunakan kelompokkelompok kecil dengan jumlah anggota tiap kelompok 4-5 orang siswa secara heterogen. Diawali dengan peyampaian materi, kegiatan kelompok,kuis, dan penghargaan kelompok.

Berdasarkan uraian diatas, maka peneliti tertarik untuk melakukan suatu penelitian tindakan kelas yang berjudul : "Meningkatkan Motivasi Belajar Siswa Dengan Menggunakan Model Kooperatif Tipe Student Teams Achievement Division (STAD) Dalam Pembelajaran IPS Di Kelas V SDN 107402 Saentis Tahun Ajaran 2015/2016".

\section{METODE PENELITIAN}

Jenis penelitian yang dilakukan adalah penelitian tindakan kelas (PTK) dengan menggunakan Model Kooperatif Tipe Student Teams Achievement Division (STAD) sebagai sasaran utama.

Penelitian ini dilaksanakan di kelas V SD Negeri Nomor 107402 Saentis Tahun Ajaran 2015/2016. Penelitian ini direncanakan selama 3 bulan (Januari, Februari, dan Maret 
2016) mulai dari kegiatan persiapan sampai pelaksanaan tindakan.

Subjek penelitian adalah siswa kelas V SD Negeri Nomor 107402 Saentis sebanyak 33 orang dengan jumlah siswa laki-laki 15 orang dan perempuan 18 orang. Penetapan kelas ini diambil berdasarkan hasil observasi terhadap kelas yang diteliti dan saran dari kepala sekolah. Objek formal dengan menggunakan model pembelajaran Kooperatif Tipe Student Teams Achievement Division (STAD).

Analisis ini dilakukan untuk mengetahui tingkat motivasi belajar siswa. Bentuk pengukuran yang dilakukan adalah sebagai berikut:

1. Adapun cara menganlisis data untuk mengetahui peningkatan motivasi belajar secara individu untuk siswa dan guru adalah dilakukan dengan menggunakan perhitungan sebagai beriku:

Motivasi Belajar $=\frac{\text { skor yang diperoleh }}{\text { Skor Maksimum }} \times 100$ (Purwanto 2011:207)

Kriteria:

* Skor 81-100 : Motivasi belajar siswa sangat tinggi

* Skor 61-80 : Motivasi belajar siswa tinggi

* Skor 0-60 : Motivasi belajar siswa rendah

2. Untuk mengukur presentase motivasi belajar siswa secara klasikal digunakan rumus sebagai berikut:

$$
\mathbf{P}=\frac{f}{n} \boldsymbol{x} 100 \%
$$

(Dewi 2014:292)
Keterangan:

$$
\begin{aligned}
& * \mathrm{P}=\text { Angka prestasi } \\
& * f=\text { Jumlah siswa yang } \\
& \text { mengalami perubahan } \\
& * n=\text { Jumlah seluruh aspek } \\
& \text { Menurut Aqib, dkk (2011:41) }
\end{aligned}
$$
tahap ini dilakukan untuk mengetahui seberapa besar tingkat keberhasilan motivasi belajar dalam \% dilakukan dengan melihat kriteria sebagai berikut:

Kriteria:

$$
\begin{aligned}
& \text { *kor } 81-100 \text { : } \\
& \text { belajar siswa sangat tinggi } \\
& \text { * } \text { Skor } 61-80 \text { : } \\
& \text { belajar siswa tinggi } \\
& \text { * } \text { Skor } 0-60 \text { : } \\
& \text { belajar siswa rendah }
\end{aligned}
$$

3. Untuk menentukan hasil angket motivasi digunakan dengan rumus:

Perubahan $=\frac{\text { Jumlah skor yang diperoleh siswa }}{\text { Jumlah skor maksimal }} \times 100 \%$ Kriteria:

$$
\begin{aligned}
& \text { *kor } 81-100: \quad \text { Motivasi } \\
& \text { belajar siswa sangat tinggi } \\
& \text { *kor } 61-80: \text { : Motivasi } \\
& \text { belajar siswa tinggi } \\
& \text { * } \text { Skor } 0-60: \text { : Motivasi } \\
& \text { belajar siswa rendah } \\
& \text { Penelitian ini direncanakan } \\
& \text { dilaksanakan di semester genap tahun }
\end{aligned}
$$$$
\text { pelajaran } 2015 \text { / } 2016 .
$$ 
ESJ VOLUME 5, NO. 2, JUNI 2016

\section{HASIL DAN PEMBAHASAN}

Tabel Motivasi Belajar Siswa

Berdasarkan Angket Kondisi Awal

\begin{tabular}{|c|c|c|c|}
\hline $\begin{array}{c}\text { No. } \\
\text { Responden }\end{array}$ & \begin{tabular}{|c|} 
Deskriptor \\
yang \\
diperoleh
\end{tabular} & Nilai & Ket. \\
\hline 1 & 30 & 37.5 & $\begin{array}{l}\text { Motivasi } \\
\text { Rendah }\end{array}$ \\
\hline 2 & 24 & 30 & $\begin{array}{l}\text { Motivasi } \\
\text { Rendah }\end{array}$ \\
\hline 3 & 29 & 36.25 & $\begin{array}{l}\text { Motivasi } \\
\text { Rendah }\end{array}$ \\
\hline 4 & 28 & 35 & $\begin{array}{l}\text { Motivasi } \\
\text { Rendah }\end{array}$ \\
\hline 5 & 47 & 58.75 & $\begin{array}{l}\text { Motivasi } \\
\text { Rendah }\end{array}$ \\
\hline 6 & 54 & 67.5 & $\begin{array}{l}\text { Motivasi } \\
\text { Tinggi }\end{array}$ \\
\hline 7 & 49 & 61.25 & $\begin{array}{l}\text { Motivasi } \\
\text { Tinggi }\end{array}$ \\
\hline 8 & 49 & 61.25 & $\begin{array}{l}\text { Motivasi } \\
\text { Tinggi }\end{array}$ \\
\hline 9 & 49 & 61.25 & $\begin{array}{l}\text { Motivasi } \\
\text { Tinggi }\end{array}$ \\
\hline 10 & 56 & 70 & $\begin{array}{l}\text { Motivasi } \\
\text { Tinggi }\end{array}$ \\
\hline 11 & 28 & 35 & $\begin{array}{l}\text { Motivasi } \\
\text { Rendah }\end{array}$ \\
\hline 12 & 27 & 33.75 & $\begin{array}{l}\text { Motivasi } \\
\text { Rendah }\end{array}$ \\
\hline 13 & 50 & 62.5 & $\begin{array}{l}\text { Motivasi } \\
\text { Tinggi }\end{array}$ \\
\hline 14 & 36 & 45 & $\begin{array}{l}\text { Motivasi } \\
\text { Rendah }\end{array}$ \\
\hline 15 & 37 & 46.25 & $\begin{array}{l}\text { Motivasi } \\
\text { Rendah }\end{array}$ \\
\hline 16 & 25 & 31.25 & $\begin{array}{l}\text { Motivasi } \\
\text { Rendah }\end{array}$ \\
\hline 17 & 26 & 32.5 & $\begin{array}{l}\text { Motivasi } \\
\text { Rendah }\end{array}$ \\
\hline 18 & 34 & 42.5 & $\begin{array}{l}\text { Motivasi } \\
\text { Rendah }\end{array}$ \\
\hline 19 & 27 & 33.75 & Motivasi \\
\hline
\end{tabular}

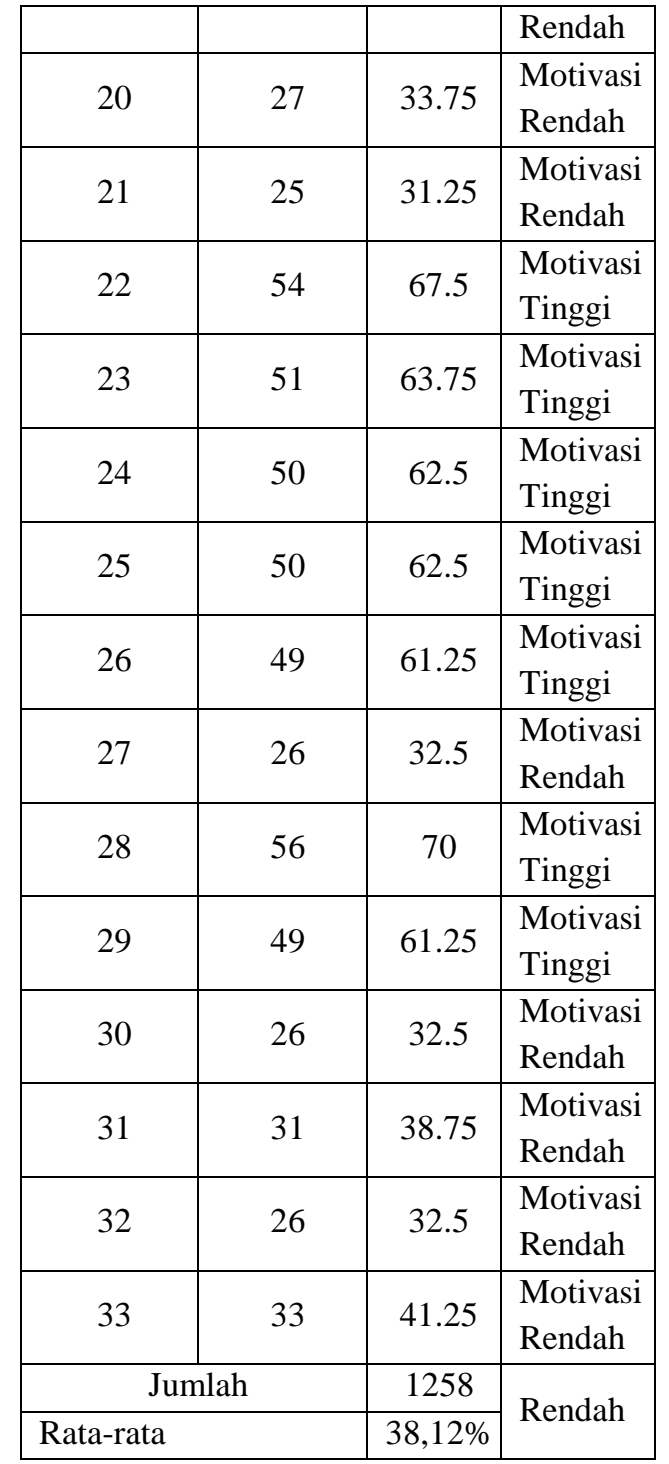

Dari data tersebut dapat dilihat bahwa masih sangat rendahnya motivasi belajar siswa terhadap pelajaran IPS. Hanya terdapat 13 siswa yang memiliki motivasi tinggi atau sebesar 39,39\% dari 33 orang siswa, sedangkan 20 siswa atau sebesar 60,60\% dari 38 siswa lainnya belum memenuhi kriteria yang diharapkan 
Herawati Bukit: Meningkatkan Motivasi Belajar ..

Tabel Rekapitulasi Observasi Motivasi Belajar Siswa

Siklus I dan Siklus II

\begin{tabular}{|c|c|c|c|c|c|}
\hline \multirow{2}{*}{$\begin{array}{c}\text { No.Urut } \\
\text { Siswa }\end{array}$} & \multicolumn{2}{|c|}{ Siklus I } & \multicolumn{2}{|c|}{ Siklus II } & \multirow[b]{2}{*}{ Keterangan } \\
\hline & Pertemuan I & Pertemuan II & Pertemuan I & Pertemuan II & \\
\hline 1 & 46,87 & 56,25 & 71,87 & 81,25 & Motivasi Sangat Tinggi \\
\hline 2 & 37,5 & 50 & 53,12 & 75 & Motivasi Tinggi \\
\hline 3 & 50 & 50 & 68,75 & 84,37 & Motivasi Sangat Tinggi \\
\hline 4 & 43,75 & 53,12 & 68,75 & 81,25 & Motivasi Sangat Tinggi \\
\hline 5 & 50 & 56,25 & 78,12 & 84,37 & Motivasi Sangat Tinggi \\
\hline 6 & 50 & 75 & 87,5 & 87,5 & Motivasi Sangat Tinggi \\
\hline 7 & 56,25 & 71,87 & 84,37 & 90,62 & Motivasi Sangat Tinggi \\
\hline 8 & 65,62 & 78,12 & 90,62 & 90,62 & Motivasi Sangat Tinggi \\
\hline 9 & 62,5 & 78,12 & 87,5 & 93,75 & Motivasi Sangat Tinggi \\
\hline 10 & 68,75 & 81,25 & 93,75 & 93,75 & Motivasi Sangat Tinggi \\
\hline 11 & 43,75 & 56,25 & 65,62 & 78,12 & Motivasi Tinggi \\
\hline 12 & 40,62 & 59,37 & 59,37 & 78,12 & Motivasi Tinggi \\
\hline 13 & 53,12 & 65,62 & 81,25 & 87,5 & Motivasi Sangat Tinggi \\
\hline 14 & 50 & 62,5 & 81,25 & 87,5 & Motivasi Sangat Tinggi \\
\hline 15 & 53,12 & 59,37 & 75 & 87,5 & Motivasi Sangat Tinggi \\
\hline 16 & 40,62 & 56,25 & 56,25 & 71,87 & Motivasi Tinggi \\
\hline 17 & 40,62 & 53,12 & 56,25 & 75 & Motivasi Tinggi \\
\hline 18 & 46,87 & 56,25 & 68,75 & 84,37 & Motivasi Sangat Tinggi \\
\hline 19 & 53,12 & 59,37 & 71,87 & 84,37 & Motivasi Sangat Tinggi \\
\hline 20 & 43,75 & 53,12 & 68,75 & 81,25 & Motivasi Sangat Tinggi \\
\hline 21 & 43,75 & 59,37 & 59,37 & 75 & Motivasi Tinggi \\
\hline 22 & 68,75 & 81,25 & 90,75 & 93,75 & Motivasi Sangat Tinggi \\
\hline 23 & 56,25 & 75 & 87,5 & 90,62 & Motivasi Sangat Tinggi \\
\hline 24 & 53,12 & 65,62 & 84,37 & 90,62 & Motivasi Sangat Tinggi \\
\hline 25 & 62,5 & 75 & 87,5 & 90,62 & Motivasi Sangat Tinggi \\
\hline 26 & 59,37 & 71,87 & 87,5 & 87,5 & Motivasi Sangat Tinggi \\
\hline 27 & 37,5 & 56,25 & 59,37 & 78,12 & Motivasi Tinggi \\
\hline 28 & 71,87 & 87,5 & 96,87 & 96,87 & Motivasi Sangat Tinggi \\
\hline 29 & 40,62 & 50 & 87,5 & 87,5 & Motivasi Sangat Tinggi \\
\hline 30 & 40,62 & 53,12 & 62,5 & 81,25 & Motivasi Sangat Tinggi \\
\hline 31 & 46,87 & 56,25 & 68,75 & 84,37 & Motivasi Sangat Tinggi \\
\hline 32 & 43,75 & 59,37 & 65,62 & 81,25 & Motivasi Sangat Tinggi \\
\hline 33 & 46,87 & 56,25 & 71,87 & 84,37 & Motivasi Sangat Tinggi \\
\hline Jumlah & 200 & 375 & 2478,18 & 2799,92 & Motivasi Sangat Tinggi \\
\hline $\begin{array}{c}\text { Nilai } \\
\text { rata-rata }\end{array}$ & $50 \%$ & $62.5 \%$ & $75.09 \%$ & $84,84 \%$ & Sangat Tinggi \\
\hline
\end{tabular}

Melalui tabel diatas peningkatan persentase motivasi belajar siswa dapat dilihat dari rata- rata nilai observasi siswa hasil siklus I dan siklus II seperti gambar berikut ini: 
Tabel Hasil Rata-rata Motivasi Belajar Siswa Siklus I Dan Siklus II

\begin{tabular}{|c|c|}
\hline Keterangan & Persentasi \\
\hline Siklus I Pertemuan 1 & $50 \%$ \\
\hline Siklus I Pertemuan 2 & $62,5 \%$ \\
\hline Siklus I Pertemuan 1 & $75,09 \%$ \\
\hline Siklus I Pertemuan 2 & $84,84 \%$ \\
\hline
\end{tabular}

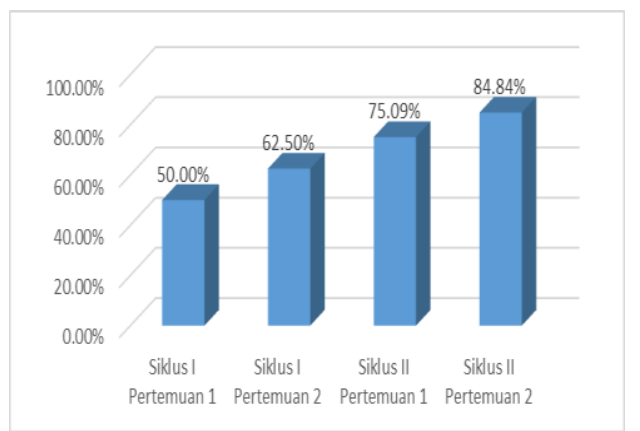

Diagram Rekapitulasi Observasi Motivasi Belajar Siswa Siklus I dan Siklus II

Dari hasil observasi di atas dapat dilihat bahwa siswa mengalami perubahan motivasi belajar dalam bentuk tekun menghadapi tugas, ulet menghadapi kesulitan, menunjukkan minat terhadap macam-macam masalah, lebih senang bekerja sendiri, dapat mempertahankan pendapatnya, bekerja sama dalam mencari dan memecahkan masalah, tidak mudah melepas hal yang diyakini, senang mencari dan memecahkan masalah soal-soal.

Tabel Rekapitulasi Observasi Kegiatan Guru Pada Siklus I dan Siklus II

\begin{tabular}{|l|l|l|}
\hline No & \multicolumn{1}{|c|}{ Aspek } & Presentasi \\
\hline 1 & Siklus I Pertemuan 1 & $58,3 \%$ \\
\hline 2 & Siklus I Pertemuan 2 & $73,61 \%$ \\
\hline 3 & Siklus II Pertemuan 1 & $84,72 \%$ \\
\hline 4 & Siklus II Pertemuan 2 & $91,66 \%$ \\
\hline
\end{tabular}

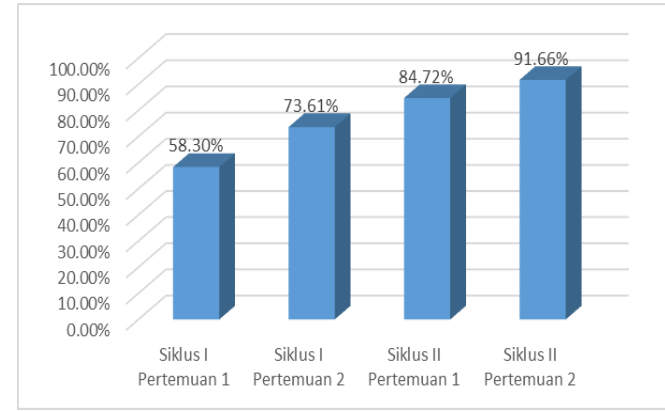

Diagram Rekapitulasi Observasi Kegiatan Guru Siklus I dan Siklus II

Dari diagram diatas, peningkatan observasi kegiatan guru dapat diuraikan sebagai berikut. Melalui model pembelajaran kooperatif tipe STAD (Student Teams Achievement Division) dapat meningkatkan motivasi belajar siswa pada pokok bahasan "Menghargai Jasa Tokoh dalam Mempersiapkan Kemerdekaan".

Dengan demikian dapat disimpilkan bahwa meningkatnya motivasi belajar siswa melalui model pembelajaran kooperatif tipe STAD (Student Teams Achievement Division) dikelas V SD Negeri 107402 Saentis Tahun Ajaran 2015/2016.

\section{KESIMPULAN}

Berdasarkan hasil penelitian tindaan kelas yang dilakukan terhadap upaya meningkatkan motivasi belajar siswa dengan menggunakan model pembelajaran kooperatif tipe STAD (Student Teams Achivemet Division) pada mata pelajaran IPS kelas V SD Negeri 107402 Saentis Tahun Ajaran 2015/2016 Pokok Bahasan Menghargai Jasa Tokoh dalam Mempersiapkan Kemerdekaan dapat disimpulkan sebagai berikut: 
1. Penerapan pembelajaran kooperatif tipe STAD (Student Teams Achivemet Division) dapat meningkatkan motivasi belajar siswa karena dapat memberikan kesempatan kepada siswa untuk belajar aktif bersama teman kelompoknya sehingga siswa tertantang untuk berusaha mengerjakan tugas tugasnya dengan mendapatkan nilai yang maksimal dalam belajar.

2. Pada kondisi awal hasil penelitian menunjukkan bahwa terjadi peningkatan motivasi belajar siswa berdasarkan angket yaitu pada kondisi awal, angka motivasi klasikal diperoleh $38,12 \%$ yang tergolong rendah dan pada kondisi akhir angka klasikal diperoleh $86,67 \%$ yang tergolong dalam kriteria sangat tinggi.

3. Dari hasil observasi motivasi belajar siswa memperlihatkan bahwa terjadi peningkatan belajar siswa diantaranya adalah sebagai berikut:

a. Pada siklus I, pertemuan 1 diperoleh data bahwa $50 \%$ yang motivasi belajarnya tergolong rendah.

b. Pada siklus I, pertemuan 2 diperoleh data bahwa $62.5 \%$ yang motivasi belajarnya tergolong tinggi.

c. Pada siklus I, pertemuan 1 diperoleh data bahwa $75.09 \%$ yang motivasi belajarnya tergolong tinggi.

d. Pada siklus II, pertemuan 2 diperoleh data bahwa $84,84 \%$ yang motivasi belajarnya tergolong sangat tinggi.

4. Dari hasil observasi kegiatan mengajar mengajar pada siklus I pertemuan 1 diperoleh skor 58,3\% tergolong rendah, pada siklus I pertemuan 2 diperoleh skor $73,61 \%$ tergolong tinggi. Dan pada siklus II pertemuan 1 diperoleh skor $84,72 \%$ tergolong sangat tinggi, pada siklus II pertemuan 2 diperoleh skor $91,66 \%$ tergolong sangat tinggi.

5. Pembelajaran dengan menggunakan model kooperatif tipe STAD (Student Teams Achivemet Division) pada pokok bahasan Menghargai Jasa Tokoh dalam Mempersiapkan Kemerdekaan dapat mengurangi kejenuhan dan kemalasan siswa dalam mengikuti pembelajaran IPS.

Berdasarkan hasil penelitian tindakan kelas ini, maka peneliti memberikan beberapa saran sebagai berikut:

1. Kepada kepala sekolah, hendaknya menghimbau guruguru khususnya dalam pembelajaran IPS, menggunakan model kooperatif tipe STAD (Student Teams Achivemet Division) supaya aktif dan kreatif dalam melaksanakan proses pembelajaran.

2. Bagi guru, disarankan agar menerapkan model-model pembelajaran kooperatif kooperatif tipe STAD (Student Teams Achivemet Division) 
khususnya dalam pembelajaran IPS agar terciptanya suasana belajar siswa yang aktif, efektif dan menyenangkan.

3. Bagi siswa, untuk menambah keaktifan dan memotivasi belajar, sehingga dapat meningkatkan motivasi belajar siswa khususnya pada pembelajaran IPS (Ilmu Pengetahuan Sosial).

4. Bagi peneliti, yang dimaksud mengadakan penelitian pada permasalahan yang sama agar mampu untuk menguasai terlebih dahulu setiap tahapan yang terdapat dalam model serta menerapkan pembelajaran kooperatif kooperatif tipe STAD (Student Teams Achivemet Division) dalam meningkatkan motivasi belajar siswa secara maksimal.

5. Bagi peneliti lain, sebagai bahan referensi yang mengadakam penelitian dengan model pembelajaran yang sama.

\section{DAFTAR RUJUKAN}

Aqib, Zainal. 2009. Penelitian Tindakan Kelas. Bandung: Yramawidya.

Dewi. 2014. Penelitian Tindakan Kelas. Medan: Pasca Sarjana Unimed.
Djamarah. 2011. Psikologi Belajar. Jakarta: PT Rineka Cipta.

Hamalik. 2010. Proses Belajar Mengajar. Jakarta: Bumi Aksara.

Istarani. 2012. Model Pembelajaran Inovatif. Medan: Media Persada.

Ridwan, Istarani. 2015. Strategi Dan Teknik Pembelajaran Kooperatif. Medan: Media Persada.

Rusman. 2014. Model-Model Pembelajaran. Jakarta: Raja Grafindo Persada.

Sardiman. 2011. Interaksi \& Motivasi Belajar Mengajar. Jakarta: Raja Grafindo Persada.

Slavin. 2015. Cooperative Learning. Bandung: Nusa Media.

Sutrisno, dkk. 2009. Ilmu Pengetahuan Sosial. Jakarta: Pusat Perbukuan Departemen Pendidikan Nasional.

Trianto. 2013. Mendesain Model Pembelajaran InovatifProgresif. Surabaya: Kencana Prenada Group.

Uno Hamza B. 2012. Teori Motivasi dan Pengukirannya. Jakarta: Bumi Aksara. 